\title{
PREFACE: SPECIAL ISSUE OF ISHMT-ASTFE HEAT AND MASS TRANSFER CONFERENCE 2017
}

Since its inception in 1971, the Indian Society for Heat and Mass Transfer (ISHMT) has been pivotal in organizing its flagship biennial event, the Indian Heat and Mass Transfer Conference (IHMTC). It has been a unique platform in bringing together experts from academia and industry for the dissemination of ideas and sharing of knowledge in the field of heat and mass transfer.

The 24th National and 2nd International ISHMT-ASTFE Heat and Mass Transfer Conference (IHMTC 2017) was organized jointly by the Birla Institute of Technology and Science (BITS) Hyderabad Campus, and the Indian Institute of Technology Hyderabad, in collaboration with the American Society of Thermal and Fluids Engineers (ASTFE). It was held at the BITS Hyderabad Campus during December 27-30, 2017. Out of the total 576 contributed papers, 71 were related to enhanced heat transfer. These were carefully screened, and the selected ones were taken up for further review. Finally, seven papers focusing on various topics of current interest in enhanced heat transfer were chosen after peer review for publication in this special issue of the Journal of Enhanced Heat Transfer.

Arvind Pattamatta is an Associate Professor in the Department of Mechanical Engineering at the Indian Institute of Technology Madras. He received his PhD from SUNY, Buffalo, NY in 2009. He is the recipient of the Alexander von Humboldt Fellowship for the year 2013, INAE Young Engineer Award for the year 2015 and JSPS Invitational Fellowship for the year 2017. His research interests are in the area micro- and nanoscale energy transport. He has authored more than 90 publications in peer-reviewed journals and conferences.

After completing his PhD at IIT Bombay, Dr. M.P. Maiya joined the Mechanical Engineering Department of IIT Madras in 1988 and is presently serving as a professor since 2004. He has supervised 22 research scholar theses and close to 100 Masters and Bachelor's degree student projects. He has published over 175 papers in international journals (70) and conferences. His research interests are sorption technology, desiccant, and evaporative cooling, air conditioning and ventilation, passive cooling of buildings, $\mathrm{CO}_{2}$ refrigeration, metal hydrides, and energy systems. His accomplishments include 50 sponsored and consultancy projects, 25 Various Educational Programs, Fellow Membership from The Institution of Engineers (India), DAAD fellowship, organizing several workshops/conferences and best paper awards, editorial board memberships and editorships in journals, membership in selection/jury committees, several international academic assignments, and contribution to various professional societies.

The guest editors appreciate the authors for their contributions and also thank all the reviewers for their prompt and critical comments. Special thanks are due to the Begell House publishing team for their cooperation. 


\section{Guest Editors:}

Arvind Pattamatta and M.P. Maiya

Department of Mechanical Engineering, Indian Institute of Technology Madras,

Chennai 600036, India 